\title{
Mechanical Behavior of Aluminum Metal Matrix Composite for Wheel Hub Application
}

\author{
P. V. Narasima Rao, Periyasamy P., Vasudeva Rao, Ramanan N., Naveen
}

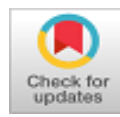

\begin{abstract}
Now the days of light weight application in a industry. In light weight application the material also strength of the material also important once. The material behavior load character station and application area also important once. The most of the material not suitable for the application. In this work the aluminum MMC material has been chosen in this work. The main focus of the work is aluminum alloys wheel hub area. The main problem is wear resistance. Generally the alloy wheel hub are with stand in a $50000 \mathrm{KM}$ in motor cycle. Then after they are wear out. When increase the hardness of the material hence the decreasing wear out corresponding wear resistance also improved. In this work the aluminum MMC as taken different level and observed which one material as chosen for the application. Finally we are discussed with fracture surface of the materials
\end{abstract}

Keywords : Wheel hub material, wear character station, Fracture surface, material Character station

\section{INTRODUCTION}

In the current scenario, Metal Matrix Composites (MMCs) are plays a vital to replace the existing conventional materials into high tribologically behaviour materials by low cost to make the world as attractive option. It is mostly used for structural applications ship, wind turbine and aerospace. The author observed of the different volume percentage of the material added in the composites and observed the character station of the materials11. The author observed that the materials differenct aluminum grades and makes a casting of the composites finally they tested and concluded of the projects. The paper has studied and prepared the Structure of hexagonal boron nitride (h-BN) consist of hexagonal layers with strong covalent bonds and weak Vander Waals bonds between them. Such specific structure and usually plate-like grains cause anisotropic properties of aluminium oxynitrideh-BN based materials with anisotropic properties. The thermal properties were found much higher in the perpendicular direction during hot pressing. The grains were found to be in plate shape3. This work has proposed and demonstrated a simple electrical resistance heat assisted pressing technique is for the surface graphitization of

Revised Manuscript Received on December 30, 2019.

* Correspondence Author

P. V. Narasima Rao*, Research Scholar, Department of Mechanical Engineering, St Peter's Institute of Higher Education and Research, Chennai, India.

P. Periyasamy, Professor, Department of Mechanical Engineering, St Peter's institute of Higher Education and Research, Chennai

Vasudeva Rao, Research Scholar, Department of Mechanical Engineering, St Peter's institute of Higher Education and Research, Chennai

Ramanan N., Sr. Engineer, Synce Engineering Service, Chennai

Naveen. E, Asst Professor, Department of Mechanical Engineering, Sri Sai Ram Engineering College, Chennai

(c) The Authors. Published by Blue Eyes Intelligence Engineering and Sciences Publication (BEIESP). This is an open access article under the CC BY-NC-ND license (http://creativecommons.org/licenses/by-nc-nd/4.0/) aluminium alloys. The aluminium substrate is first coated with a graphitic layer by solution casting. Raman spectroscopic observed of the graphitized surface shows a significant shift in major graphitic peaks with an increase in the intensity ratio (ID/IG). The graphitised surface shows new graphite peaks and increase in the intensity ratio. No peaks were were found corresponding to the aluminium. The surface was found to be five times harder than the normal surface4. In this project improved the corrosion resistance of the material . when added the oxide in a material they has prevent the coression resistance. In the author produced by the way of the different oxide based composite and finally concluded the results5. The project was prepared the Metal matrix composites in the aluminium oxynitride-hexagonal boron nitride system with anisotropic properties by using SHS technique to obtain complex powders with both phases6. In this work has been done in the different percentage composite material was prepared and finally tested and concluded the composites 7. Formation of alumina $\left(\mathrm{Al}_{2} \mathrm{O}_{3}\right)$ was detected in X-ray diffraction studies but no peaks corresponding to aluminium carbide $\left(\mathrm{Al}_{4} \mathrm{C}_{3}\right)$ was observed. The surface mechanical properties were evaluated through microhardness testing. The surface hardness depends mainly on the processing parameters and subsequently the amount of graphite flakes impregnated on to the surface 8 . The aluminium substrate is first coated with a graphitic layer by solution casting. In the way preheated the composite and make a casting of the composite. Finally they tested of the composites and concluded the results9. K. Jeshurun lijay et al (10) was studied the field emission scanning electron microscope (FESEM) and electron backscatter diffraction (EBSD) for and found the TiC particles were characterized with homogeneous distribution, clear interface, good bonding and various shapes such as cubic, spherical and hexagonal. EBSD maps showed the grain refinement action of TiC particles on the produced composites of the prepared AA6061/TiC AMCs.

\section{MATERIALS AND METHODS}

The following material are chosen in this work Al 6061, Sic various percentages, the percentages shown in a figures. The objective of the material selection is to observed of the wear character station of the materials

\section{PROCESS METHODOLOGY}

Stir casting process is the one of the best process for castings it having the vast measurable parameters such as processing temperature and holding time on the uniform distribution of particles and resulting in good mechanical properties such as Tensile, ductility, hardness and impact behaviour. In this process increase the particles cluster corresponding to an increase in the processing temperatures.

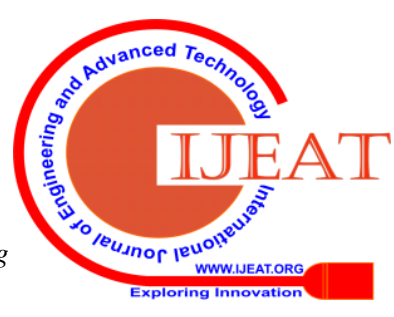


Which were stirred for a constant speed with longer period at higher temperature, the particles were agglomerated in the melt. The schematic diagram of stir casting process is shown in fig. 1

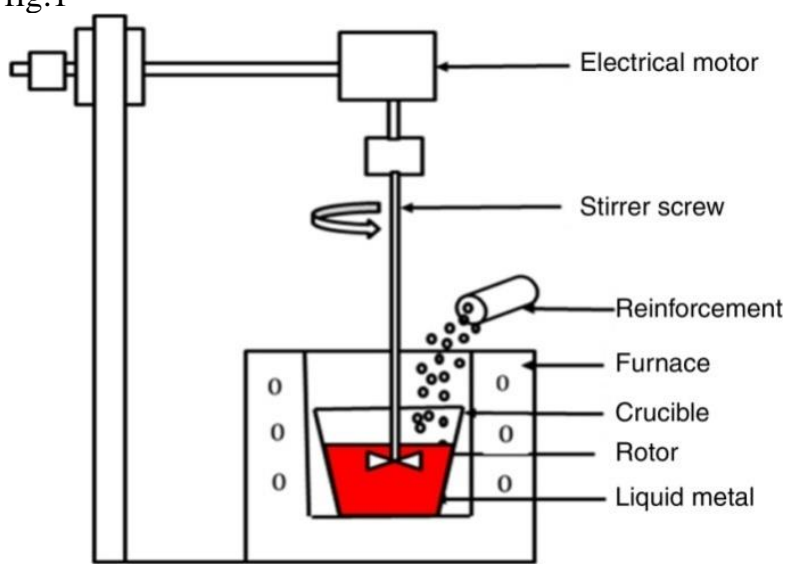

Fig.1. Stir casting process setup

Composition of Metal Matrix composite

Table.1. Casting calculation

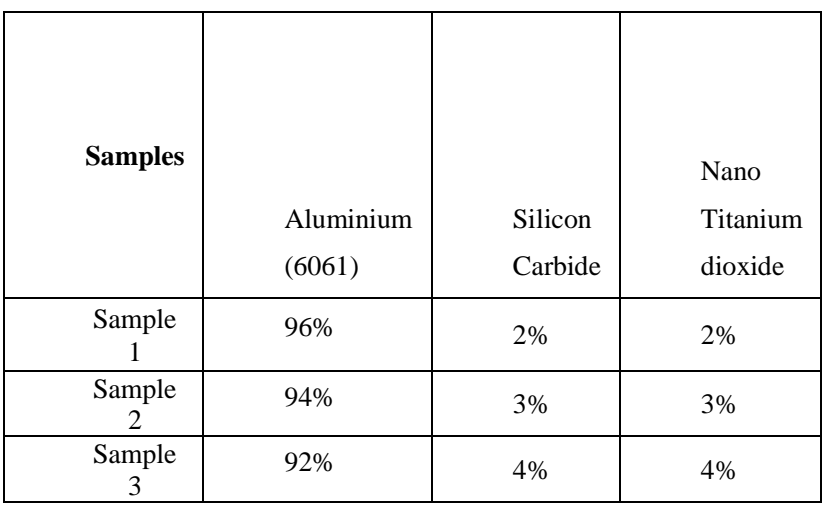

\section{Testing of Composite}

The different type of tests that the materials were subjected to testing's to found their mechanical properties

\subsection{Tensile test}

The tensile test image shown in figure below. The test specimen as per ASTM Standard. The standards shown in table below the figures

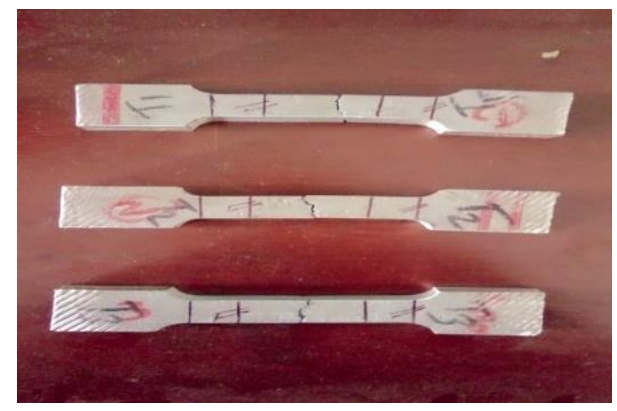

Fig. 2 Tensile test specimen

\subsection{Flexural test}

The Flexural test image shown in figure below. The test specimen as per ASTM Standard. The standards shown in table below the figures

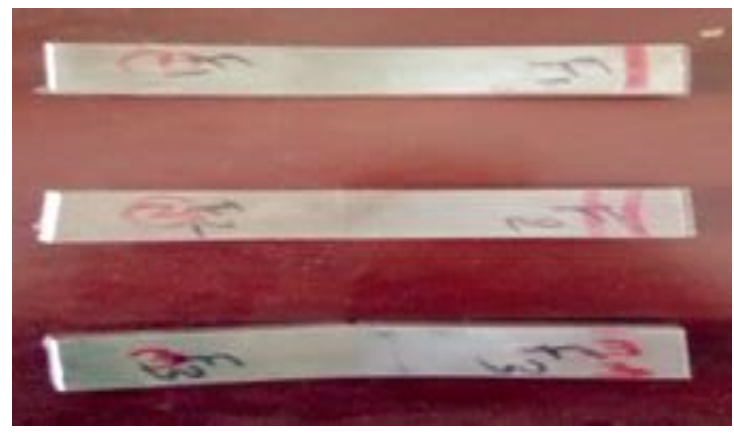

Fig. 3 Flexural test samples

\subsection{Impact test}

The Impact test image shown in figure below. The test specimen as per ASTM Standard. The standards shown in table below the figures

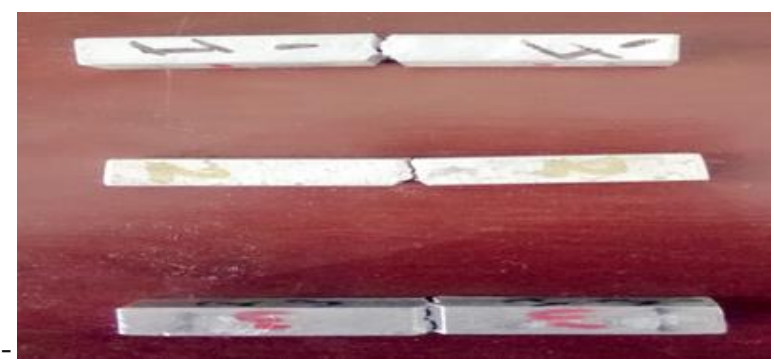

Fig. 4 Impact Test Specimen

Table . 2 Testing Standards

\begin{tabular}{|c|c|}
\hline \multicolumn{2}{|c|}{ [1] Testing Standards } \\
\hline Tensile Test & ASTM: B-557M \\
\hline Flexural test & ASTM: A-370 \\
\hline Impact test & IS: 1757 \\
\hline
\end{tabular}

\section{RESULT AND DISCUSSION}

The results of the tests are discussed below

\subsection{Tensile Test}

Table . 3. TensileTesting Standards

\begin{tabular}{|c|c|c|c|c|}
\hline $\begin{array}{l}\text { Sam } \\
\text { ples }\end{array}$ & $\begin{array}{l}\quad \text { F } \\
\text { max } \\
(\mathbf{k N}) \\
\end{array}$ & $\begin{array}{l}\text { UTS } \\
\text { (Mpa) }\end{array}$ & $\begin{array}{ll} & \% \text { Elongat } \\
\text { ion } & \\
\end{array}$ & $\begin{array}{l}\quad \text { Yi } \\
\text { eld } \\
\text { Stress } \\
\text { (Mpa) }\end{array}$ \\
\hline ple ${ }^{\text {Sam }}$ & $.08^{8}$ & 57.72 & 5.06 & 52.68 \\
\hline ple ${ }^{\text {Sam }}$ & $2.11^{1}$ & 92.22 & 7.63 & 66.61 \\
\hline Sample 3 & 20.85 & 164.06 & 7.63 & 110.53 \\
\hline
\end{tabular}

Published By:

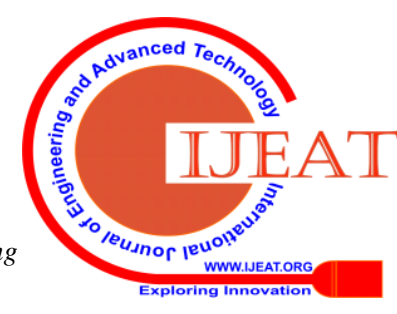




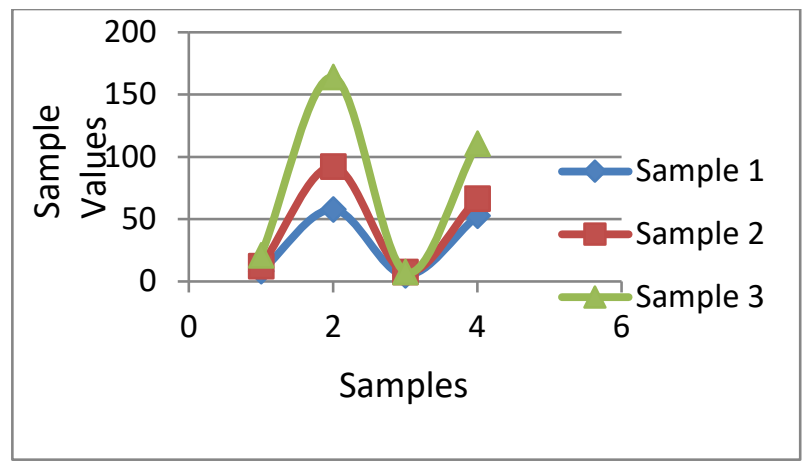

Fig 5. Tensile data Result

The tensile test output result shown in graphs. The graphs shown in a the maximum ultimate tensile strength the sample no 3 . The corresponding all data shown in tables

\section{Flexural test}

\begin{tabular}{|c|c|c|}
\hline Sl.No & $\begin{array}{l}\text { Sample } \\
\text { No }\end{array}$ & $\begin{array}{l}\mathbf{F}_{\max } \\
\text { in } \mathbf{k N}\end{array}$ \\
\hline 1 & 1 & 4.58 \\
\hline 2 & 2 & 5.57 \\
\hline 3 & 3 & 4.40 \\
\hline
\end{tabular}

Table . 4. Flexural Testing Result

The Flexural test output result shown in graphs. The graphs shown in a the maximum ultimate tensile strength the sample no 2 . The corresponding all data shown in tables

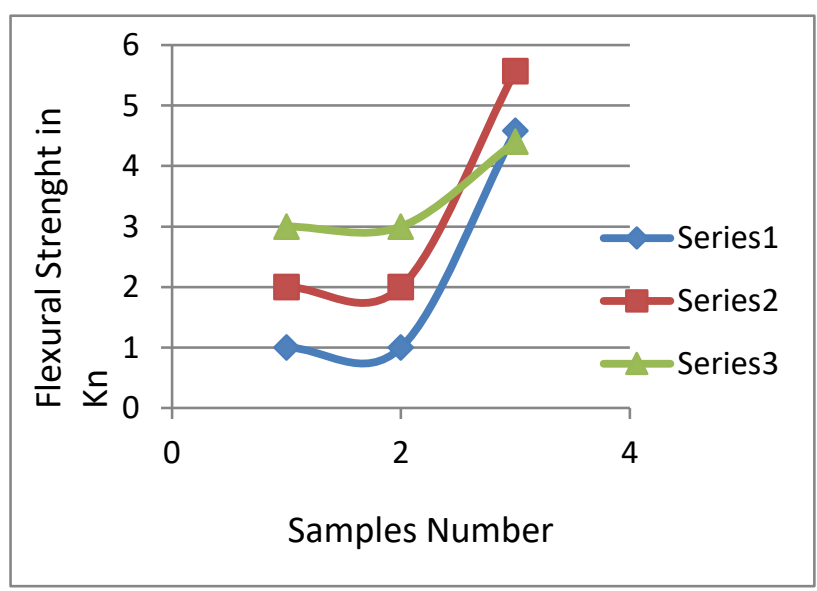

Fig 6. Flexural data Result

The Impact test output result shown in graphs. The graphs shown in a the maximum ultimate tensile strength the sample no 3 . The corresponding all data shown in tables

\subsection{Impact test}

Table . 5. Impact Test Result

\begin{tabular}{|c|c|c|}
\hline Sl.No & Sample no & Value \\
\hline 1 & 1 & 8 joules \\
\hline 2 & 2 & 7 joules \\
\hline 3 & 3 & 12 joules \\
\hline
\end{tabular}

Published By:

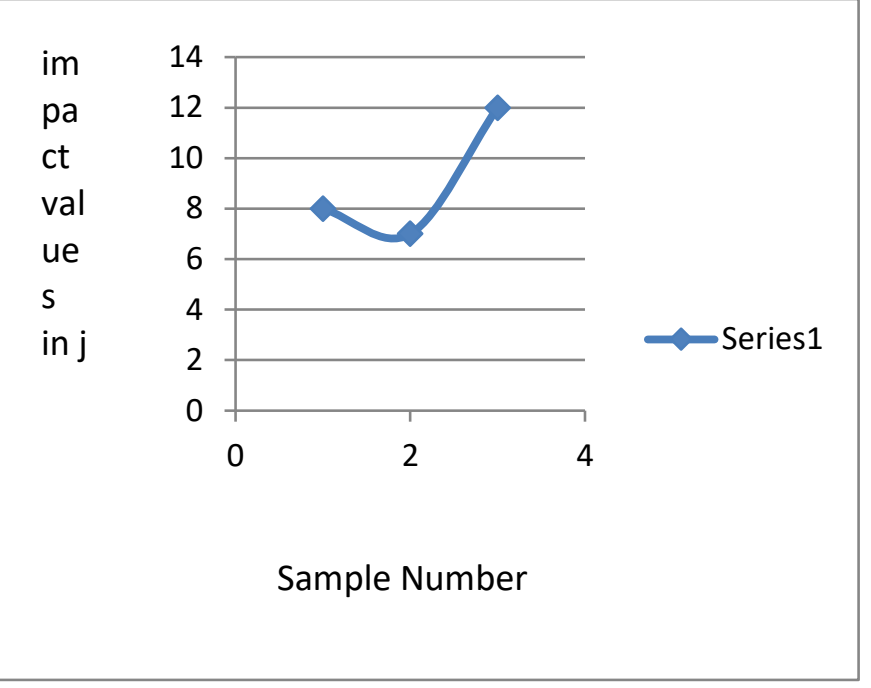

Fig 8. Impact data Result

\subsection{Hardness test}

Table . 6. Hardness Test Result

\begin{tabular}{|l|l|}
\hline [2] Sl.No & $\begin{array}{l}\text { [3] Hardness valve In } \\
\text { HRB }\end{array}$ \\
\hline$[4] 1$ & {$[5] 39$} \\
\hline$[6] 2$ & {$[7] 40$} \\
\hline$[8] 3$ & {$[9] 44$} \\
\hline$[10] 4$ & {$[11] 42$} \\
\hline$[12] 5$ & {$[13] 46$} \\
\hline
\end{tabular}

The Hardness test output result shown in graphs. The graphs shown in a the maximum ultimate tensile strength the sample no 5. The corresponding all data shown in tables

Scanning Electron Microscope Observed
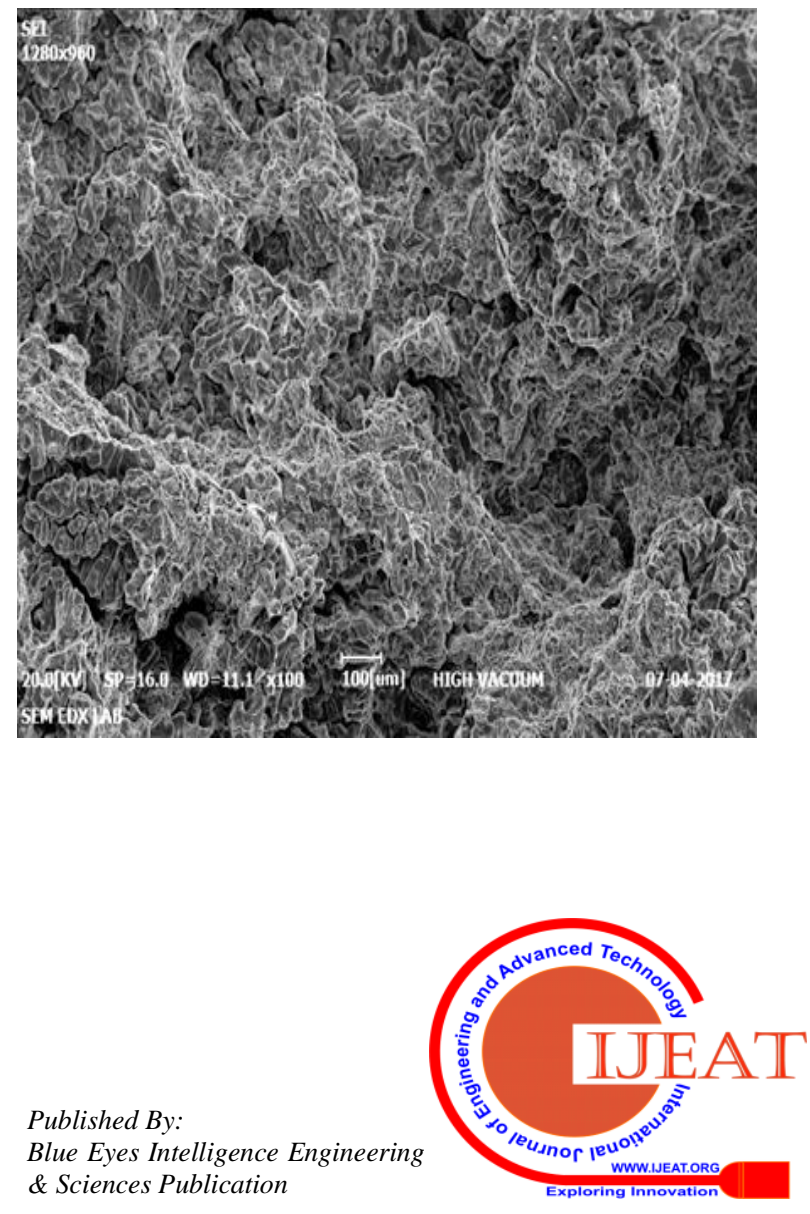


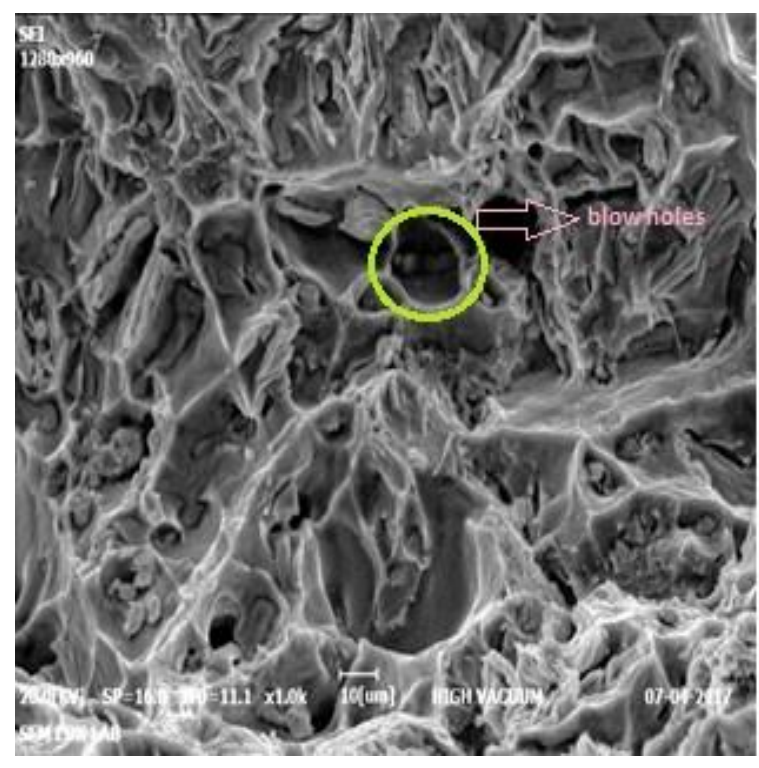

Fig 9. SEM image for tensile load specimen
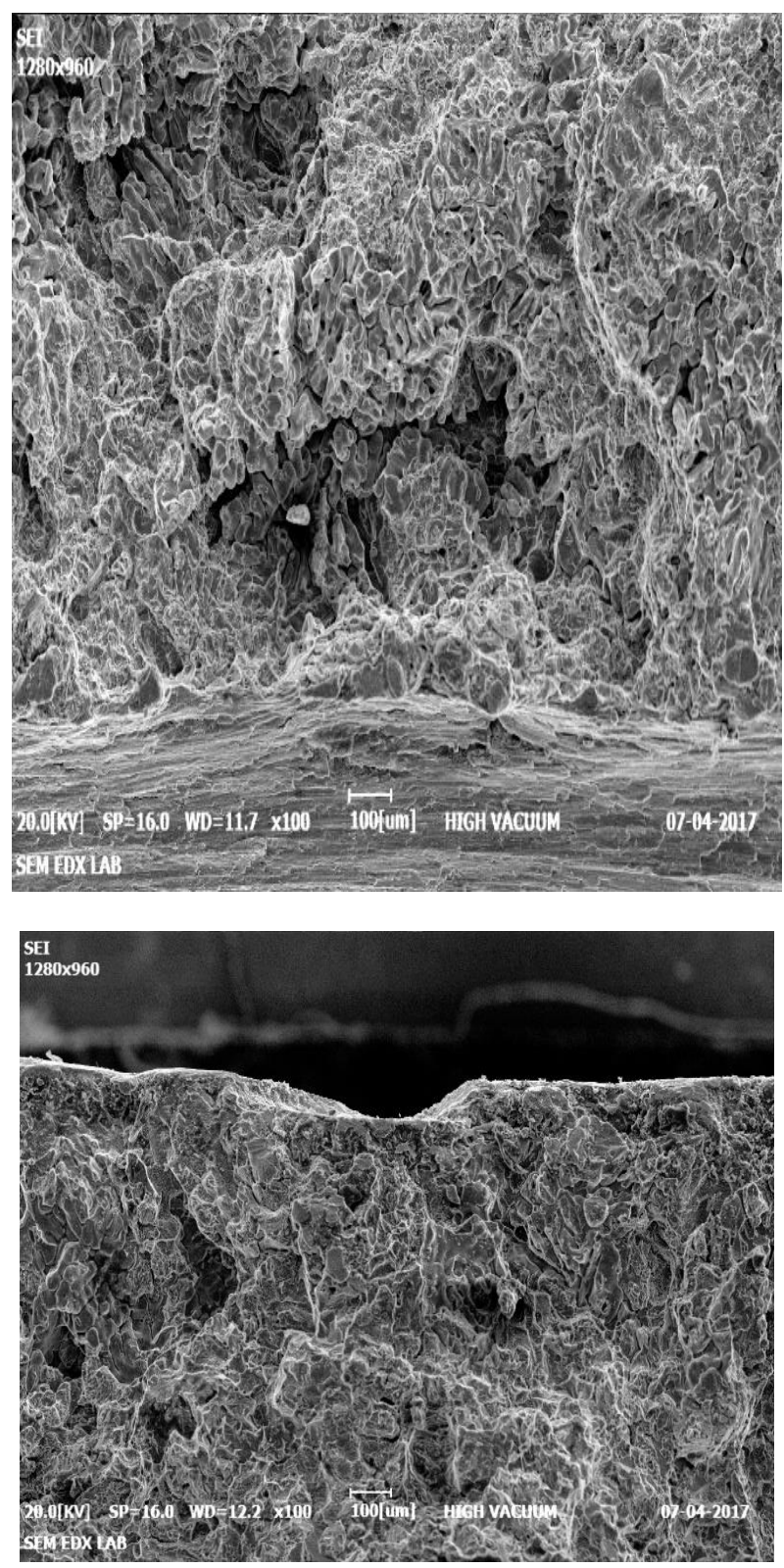

Fig 10.SEM image of impact sample
Fig $9 \& 10$. Shows that the image as ductile fracture surface. The image shown that cup and cone. Hence the fracture has been ductile. And distribution of particles showed in figures. The nano particles also shown in figures.

\section{CONCLUSION}

The result shown that the aluminum composite material used in a wheel rim application. The result shown that the tensile, flexural,impact and hardness test results as different composites. The result shown in the which one the best results. The sem image also shown in the fracture surface of the material. The material formed in the cup and cone shapes. The images shown in the ductile fracture surface. Hence we concluded that the higher hardiness value can be wear resistance of the material.

\section{REFERENCES}

1. İsmail ÖzdemirFang Chai, Datong Zhang , Yuanyuan Li(2000)"Structural observed of aluminium and Silicon carbide composites" (Vol 60, Issue 3, 2000, pp 411-419)

2. Hui-xueJIANGThomas(2011)"Bonding of three layer metal in aluminium composites under stress conditions" Hui-xueJIANG,Thomas . (Vol 21, Issue 8, , Pp 1692-1697)

3. Agnieszka,Hernández-SilWilk et al(2016)“Aluminium Oxy nitriode hexagonal boron nitride composites with anisotropic properties" (Vol 36, Issue 8, , Pp) 2087-2092

4. BaidehishSahoo et-al (2017):Preparation of Aluminium 6063 Graphite surface composite by an electrical resistance heat assisted pressing technique (Vol 309, , PP 563-572)

5. Sergey Vorozhtsov et-al Structural and mechanical properties of aluminium based composites processed by explosive compaction (Vol313, 15 May 2Pages 251-259)

6. D.H John, M.A Qian, M.A.Easton, P.Cao,Z.Hildebrand,Metall.mater.trans A36 A 2005 1669-1679.

7. UgenderSingarapu, Kumar adepu, Somi Reddy Arumalle Influence of Tool Material and rotational speed on Mechanical properties of friction stir welded AZ31B Magnesium Alloy.

8. Fang Chai, Datong Zhang, Yuanyuan Li Microstructures and tensile properties of submerged friction stir processed AZ91 magnesium alloy.

9. M.A. García-Bernal , R.S. Mishra , R. Verma , D. Hernández-Silva Influence of friction stir processing tool design on microstructure and superplastic behavior of Al-Mg alloys.

10. Yaobin Wang, Yongxian Huang, XiangchenMeng, Long Wan, Jicai Feng Microstructural evolution and mechanical properties of Mg-Zn-Y-Zr.

\section{AUTHORS PROFILE}

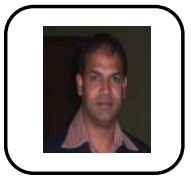

Vasudeva Rao, was UG Degree from Dr MGR Educational and Research Institute, and PG from ANNA University, he has more than 20 years of the industry Experience. He has got many awards from industry

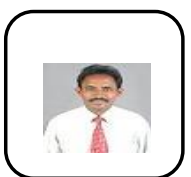

Periyasamy.P, Was UG Degree form annamalai university and PG degree same university. He has completed Doctorate from Anna university. He has got a many awards from various boars. He has more than 20 years of teaching experience

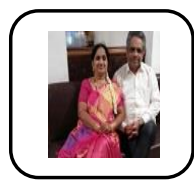

P.V. Narasima Rao He has completed UG degree form Andra university and PG from BHU Varanasi. He has more than 25 years of the industry experience. He has got many awards from industries.

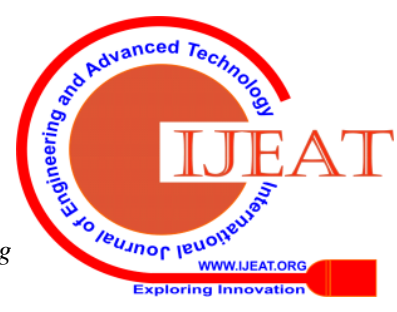

